\title{
Immediate effect of nonspecific mandibular mobilization on postural control in subjects with temporomandibular disorder: a single-blind, randomized, controlled clinical trial
}

Ana P. Amaral ${ }^{1}$, Fabiano Politti ${ }^{2}$, Yasmin E. Hage ${ }^{1}$, Eric E. C. Arruda ${ }^{1}$, Cesar F. Amorin ${ }^{3}$, Daniela A. Biasotto-Gonzalez ${ }^{1}$

\begin{abstract}
Background: Temporomandibular disorder (TMD) is considered multifactorial and is defined as a group of pain conditions characterized by functional stomatognathic system alterations, which may be affected by or related disrupted postural control. Objective: Assess the immediate effect of nonspecific mandibular mobilization (NMM) on the postural control of subjects diagnosed or not with TMD. Method: A simple-blind, randomized, controlled clinical trial was performed involving 50 subjects of both genders assigned to two groups: the TMD group and the control group. TMD was diagnosed according to the Research Diagnostic Criteria for Temporomandibular Disorders (RDC/TMD). A stabilometric assessment was performed by testing subjects in a quiet stance on a dual force platform under two visual conditions (eyes open and eyes closed). The Center of Pressure (CoP)-related variables analyzed were displacement, amplitude, speed of anterior-posterior (AP) and medial-lateral (ML) displacements and CoP sway area. The mean values of each variable were compared, considering the accepted significance value of $p<0.05$. Results: A significant difference between the pre- and post-NMM means could be observed in subjects diagnosed with TMD under the closed-eyes visual condition. There was a statistically significant difference in the $\mathrm{CoP}$ sway area $(\mathrm{p}<0.03)$ in the $\mathrm{ML}$ displacement $\mathrm{COP}$ $(\mathrm{p}<0.006)$ and $\mathrm{ML}$ amplitude $\mathrm{COP}_{\mathrm{ML}}(\mathrm{p}<0.01)$ and in the variable speed in the $\mathrm{APCOP}_{\mathrm{AP}}(\mathrm{p}<0.03)$ and $\mathrm{MLCOP} \mathrm{ML}_{\mathrm{ML}}(\mathrm{p}<0.03)$ directions, simultaneously. Conclusion: These results indicate that nonspecific temporomandibular joint mobilization contributes to the immediate improvement of postural control in patients with TMD.
\end{abstract}

Keywords: physical therapy; temporomandibular joint; temporomandibular joint disorders; equilibrioception. Article registered in the Brazilian Registry of Clinical Trials (Registro de Ensaio Clinico Brasileiro, REBEC): RBR-63gdgg HOW TO CITE THIS ARTICLE

Amaral AP, Politti F, Hage YE, Arruda EEC, Amorin CF, Biasotto-Gonzalez DA. Immediate effect of nonspecific mandibular mobilization on postural control in subjects with temporomandibular disorder: a single-blind, randomized, controlled clinical trial. Braz J Phys Ther. 2013 Mar-Apr; 17(2):121-127. http://dx.doi.org/10.1590/S1413-35552012005000075

\section{Introduction}

Temporomandibular joint disorder (TMD) is a multifactorial condition ${ }^{1,2}$ with various symptoms that may compromise the functional unit of the entire stomatognathic system, including the ligaments, muscles, articular disk and the joint itself $f^{3-5}$. The disorder is defined as a group of pain conditions characterized not by necessarily symptomatic pathologies but rather by functional alterations in the masticatory system, which can be classified into muscular and $\operatorname{articular}^{6}$ and are most common in women ${ }^{7,8}$.
Considering the need to design precise parameters for data collection and the preparation of clinical diagnoses regarding TMD ${ }^{9}$, the Research Diagnostic Criteria for Temporomandibular Disorder - RDC/ $\mathrm{TMD}^{10}$ was developed in English and subsequently adapted to $^{11}$, translated into ${ }^{12}$, and validated for Portuguese $^{13,14}$. This adaptation enabled its use in research conducted in the Brazilian population.

Thus, the RDC/TMD is a specific dual-axis system providing descriptions of the physical (axis I) and psychosocial (axis II) aspects of the evaluated subjects. This system serves as an organized and

\footnotetext{
${ }^{1}$ Graduate School Program in Rehabilitation Sciences, Universidade Nove de Julho (UNINOVE), São Paulo, SP, Brazil

${ }^{2}$ Department of Physical Therapy, UNINOVE, São Paulo, SP, Brazil

${ }^{3}$ Graduate School Program in Physical Therapy, Universidade da Cidade de São Paulo (UNICID), São Paulo, SP, Brazil

Received: 02/16/2012 Revised: 10/10/2012 Accepted: 11/20/2012
} 
efficient structure for the diagnosis of TMD ${ }^{15}$ and may be reliably used as an evaluation index for clinical interventions, unlike other questionnaires ${ }^{16}$.

A growing number of research studies ${ }^{17-21}$ have examined a possible functional link between the stomatognathic system component dysfunction and postural control, especially TMD, in addition to using the RDC/TMD to characterize TMD.

The neurofunctional organization of the stomatognathic system is a major piece of evidence supporting the possible effect of this system on postural control. This potential relationship results from the presence of sensorimotor peripheral neural connections from the stomatognathic system. The relationship may involve the association between proprioception in the stomatognathic system and the masticatory muscle receptors, including the neuromuscular spindle and Golgi tendon organ ${ }^{22}$, periodontal ligament receptors ${ }^{23,24}$, and the free nerve endings in the temporomandibular joint synovial space $^{25}$, which are all directly related to the trigeminal sensorimotor circuit $\mathrm{t}^{25-27}$.

Therefore, the neurological relationship between the stomatognathic system and postural control can be attributed to the functional connection to the trigeminal nerve nucleus motor neuron, which is affected by the Central Nervous System (CNS), as previously determined experimentally ${ }^{18}$. Thus, the evidence supporting the interaction between the trigeminal system and the vestibular nuclei ${ }^{27,28}$, with a possible alteration in the visual system and postural stability ${ }^{18}$, strengthens the argument for a relationship between the stomatognathic system and postural control.

In terms of the interaction between the visual and postural systems, alterations in visual acuity have been previously reported to compromise postural control $^{29}$, and the complete loss of eyesight hampers compensatory and anticipatory postural adjustments ${ }^{30}$. These observations indicate the importance of visual afference in preventive and compensatory corrections during posture maintenance.

Thus, the functioning of the above-described sensory afferents may presumably result in the reorganization of postural control and, consequently, generate an alteration in equilibrioception. The observed differences in body sway between healthy controls and TMD subjects corroborate this possibility ${ }^{31}$.

Regarding the treatment of this pathology, improvement and cure have also been demonstrated using a physical therapy approach, which is considered to be as effective as other treatments, including dentistry, speech therapy, and medication ${ }^{32-34}$.
Among the physical therapy resources, nonspecific mandibular mobilization (NMM) has been considered to be a valid option in the treatment of TMD ${ }^{35}$. The argument for the indication of this technique is based on the possibility of joint motion enhancing the function between the joint surfaces, eliminating soft tissue contractures and restoring muscle length, thereby promoting an analgesic effect with consequent improvement in mouth opening and laterality, which are decreased in patients with $\mathrm{TMD}^{2}$.

However, these effects are not yet fully understood, prompting the development of new studies that may provide a better understanding of the neurophysiological or clinical responses to this treatment method. Thus, expanding the knowledge about this subject can contribute to designing new therapeutic strategies for patients with TMD.

All of these previous observations have helped to formulate the hypothesis that immediate NMM can inhibit nociceptive stimuli provided by TMD and affect postural control in subjects diagnosed with TMD by reprogramming the sensory afferents, mainly in the eyes-closed visual condition.

The aim of this study was to analyze the immediate effect of NMM on postural control in patients diagnosed with TMD or not in two visual conditions: eyes open and eyes closed.

\section{Method}

\section{Sample}

The sample was set based on a pilot study with five healthy subjects, with a mean age of $29.6 \pm 2.1$ years, a mean height of $169.2 \pm 11.7 \mathrm{~cm}$, and a mean body mass of $75.48 \pm 17.7 \mathrm{Kg}$.

The highest standard deviation (SD) and mean value from sway area measurements collected before (M0) and after (M1) nonspecific mobilization were used in the sample calculations. The eyes-open condition showed a sample value of 13 subjects $(\mathrm{M} 0=1.11, \mathrm{M} 1=1.44, \mathrm{SD}=0.9)$, and the eyes closed condition showed a sample value of 24 subjects $(\mathrm{M} 0=1.82, \mathrm{M} 1=1.62, \mathrm{SD}=1.84)$, assuming a statistical power of 0.99 .

Data were collected from 140 consecutive subjects who sought the laboratory. Of those subjects, 32 were excluded because they met the exclusion criteria of the study, thus providing a sample of 108 subjects of both genders, comprising 38 controls and 70 subjects with TMD. Twenty-five subjects for each group were selected randomly from that sample using random 
number-generation software, producing a total sample composed of 50 subjects.

The inclusion criteria for participation in this clinical trial were age between 20 and 40 years ${ }^{36}$ with full permanent dentition. The TMD group had TMD, mandibular deviation, or deflection, and the control group did not have TMD. The study exclusion criteria were crossbite, open bite, or overbite; prognathism or retrognathism; using any type of dental prosthesis; undergoing orthodontic treatment or physical therapy; neurological and/or orthopedic disorders affecting body balance, as reported by the subjects, who presented exams whenever necessary; using orthopedic insoles; having low blood pressure (BP); auditory and/or vestibular alterations that could affect balance, as reported by the subjects, who presented exams whenever necessary; using medication that could affect the balance; age below 20 years and above 40 years; being overweight, as analyzed using the Body Mass Index (BMI); and having consumed alcohol in the 24 hours before the assessment.

All participants received information about the procedures and research protocol and signed a statement agreeing to participate, in accordance with Resolution 196/96 of the National Health Council (Resolução 196/96 do Conselho Nacional de Saúde). This study was approved by the Ethics Committee on Human Research, Universidade Nove de Julho, São Paulo, SP, case No. 410469/2010.

Thus, RDC/TMD was applied to 50 subjects, 25 from the TMD group (21 females and four males; mean age: $27.96 \pm 5.84$ years; mean body mass: $64.84 \pm 9.17 \mathrm{Kg}$; and mean height: $165.88 \pm 7.40$ ) and 25 from the control group (15 females and ten males; mean age: $26.52 \pm 5.24$; mean body mass: $72.20 \pm 15.35$; and mean height: $170.80 \pm 10.31 \mathrm{~cm}$ ). Each evaluation was individually performed by two experienced raters, who were trained and calibrated for applying the RDC/TMD according to the International RDC/TMD Consortium guidelines. The raters and subjects were kept blind to the group allocation.

\section{Procedures and data collection}

All subjects were submitted to two evaluations on the platform following the application of the RDC/ TMD, axis I and axis II, after a 10-minute rest on the stretcher in the supine position and immediately after NMM, respectively. The 10 minutes of rest was set because the NMM takes place for 10 minutes in the supine position.

All subjects received NMM, which was performed with the patient in the supine position on a stretcher by an experienced and previously trained therapist. Disposable gloves were used, and the fifth finger was positioned on top of the second or third molar (if present) to perform the NMM intermittently and lightly just one minute for five replicates. The mouth was opened ten times between each mobilization, with the tip of the tongue touching the incisive papilla, which promotes local relaxation. The mandibular side to be mobilized was determined ahead of time based on the diagnosis performed using the RDC/ TMD, involving one or both sides, depending on the diagnosis. The therapist remained standing on the side opposite the mandibular mobilization, thereby avoiding any pressure on the jaw and exclusively performing 1 -millimeter displacement into mandibular protrusion ${ }^{2}$.

For the stabilometric evaluation, the subjects were instructed to remain standing barefoot on the platform with their arms along their body, staring an object placed at a distance of 1 meter $^{36}$ and at the height of each patient's glabellar region. The duration of each trial was 70 seconds for both visual conditions (eyes open and eyes closed) with a 10 -second interval between each trial. Two randomly chosen trials were performed for each visual condition.

The stabilometric signals were acquired using a BIOMEC 400v1.1 (EMG System do Brasil ${ }^{\circledR}$ ) portable force platform consisting of four load cells capable of supporting $150 \mathrm{~kg}$.

Following the data collection, the values for the anterior-posterior $\left(\mathrm{CoP}_{\mathrm{AP}}\right)$ and medial-lateral $\left(\mathrm{CoP}_{\mathrm{ML}}\right)$ displacements were filtered using a fourth-order Butterworth filter at $8 \mathrm{~Hz}$ low-pass frequency prior to being used for computing the center of pressure (CoP) sway.

The following variables were calculated after those procedures: the displacement area, assessed by adjusting an ellipse to include $95 \%$ of the area covered by the CoP movement ${ }^{37}$; mean displacement in each direction $\left(\mathrm{CoP}_{\mathrm{AP}}\right.$ and $\left.\mathrm{CoP}_{\mathrm{ML}}\right)$, calculated from the sum of the distances between all consecutive points defined by the CoP trajectory divided by the number of points ${ }^{38}$; displacement amplitude, defined as the difference between the maximum and minimum displacement ${ }^{39}$; and sway speed, calculated from the CoP total displacement divided by the time period $^{39}$.

The first $10 \mathrm{~s}$ of the trial (out of a total of $60 \mathrm{~s}$ ) were disregarded to mitigate the possible effects of the subject's initial adaptation to the platform when calculating the mean values and standard deviation of the CoP displacement area and displacement, amplitude and sway speed in the anterior-posterior 
$\left(\mathrm{CoP}_{\mathrm{AP}}\right)$, and medial-lateral $\left(\mathrm{CoP}_{\mathrm{ML}}\right)$ directions of each variable. Thus, the stabilometric values collected premobilization (pre-M) and post-mobilization (post-M) were compared in both visual conditions (eyes open and eyes closed) in the control group (without TMD) and TMD group.

The extraction and processing of the signal variables assessed on the platform were performed using the MATLAB software, version 7.1 (MathWorks Inc., Natick, Massachusetts, U.S.A.).

\section{Statistical analysis}

Data distribution was assessed using the ShapiroWilk test, and the data exhibited an asymmetric distribution. The Wilcoxon signed-rank test was used for multiple comparisons between pre- and post-NMM times. The significance level adopted was $\mathrm{p}<0.05$. All data collected were analyzed using SPSS 17.0 software (SPSS Inc., Chicago, U.S.A).

\section{Results}

The comparison of the mean values of the data collected between the pre-M and post-M conditions enabled the identification of alterations exclusive to the TMD group under the eyes-closed visual condition (Table 1 ). There were statistically significant differences in the CoP sway area $(\mathrm{p}<0.03)$, $\mathrm{CoP}_{\mathrm{ML}}$ displacement $(\mathrm{p}<0.006), \mathrm{CoP}_{\mathrm{ML}}$ amplitude $(\mathrm{p}<0.01)$ and in the $\mathrm{CoP}_{\mathrm{AP}}(\mathrm{p}<0.03)$ and $\mathrm{CoP}_{\mathrm{ML}}$ $(\mathrm{p}<0.03)$ speed variable.

\section{Discussion}

Based on the results of this study, we observed that equilibrioception was affected by NMM of the temporomandibular joint (TMJ), and the response intensity was dependent on the visual information and clinical conditions of the joint. This observation can be explained by the decreases in most of the dependent variables following TMJ mobilization (Table 1), with a significant difference in the group of subjects with TMD under the eyes-closed condition.

In general, the decrease in the CoP values in both groups analyzed indicates an improvement in equilibrioception ${ }^{40}$, and the afferent stimulus provided by TMJ mobilization to the trigeminal system may be one explanation for the CoP decrease.

This potential function of the trigeminal system in the maintenance of postural control has been described in previous studies ${ }^{41-43}$. Another fact that also suggests this possibility is the confirmation of numerous anatomical connections between the trigeminal and nervous systems and structures involved in maintaining posture $27,44,45$.

Furthermore, alterations in the stomatognathic system, derived from TMJ and/or mastication muscles, may contribute to changes in postural control, as demonstrated under unilateral trigeminal nerve anesthesia ${ }^{18}$. These alterations may also produce continuous nociceptive impulses for the spinal trigeminal nucleus ${ }^{46}$ and cause the increased instability observed in patients with $\mathrm{TMD}^{47}$.

Table 1. Mean and standard deviation of sway area and displacement and amplitude of the CoP sway speed in the anterior-posterior (AP) and medial-lateral (ML) directions observed in the control and TMD groups, assessed under two visual conditions (eyes open and eyes closed) and times, pre (pre-M) and post-mobilization (post-M).

\begin{tabular}{ccccccc} 
Sway area & \multicolumn{2}{c}{ Mean displacement $(\mathrm{cm})$} & \multicolumn{2}{c}{ Amplitude $(\mathrm{cm})$} & \multicolumn{2}{c}{ Mean speed $(\mathrm{cm} / \mathrm{s})$} \\
$\left(\mathbf{c m}^{2}\right)$ & AP & ML & AP & ML & AP & ML
\end{tabular}

Eyes Open

$\begin{array}{llllllll}\text { Pre-M Control } & 2.21 \pm 1.62 & 0.33 \pm 0.14 & 0.20 \pm 0.06 & 2.0 \pm 0.62 & 1.3 \pm 0.43 & 0.54 \pm 0.12 & 0.40 \pm 0.09 \\ \text { Post-M Control } & 1.73 \pm 1.09 & 0.34 \pm 0.15 & 0.19 \pm 0.06 & 2.1 \pm 0.75 & 1.3 \pm 0.57 & 0.52 \pm 0.11 & 0.41 \pm 0.11 \\ \text { Pre-M TMD } & 1.80 \pm 1.52 & 0.32 \pm 0.14 & 0.19 \pm 0.07 & 2.0 \pm 0.73 & 1.3 \pm 0,53 & 0.53 \pm 0.12 & 0.40 \pm 0.06 \\ \text { Post-M TMD } & 1.43 \pm 0.85 & 0.29 \pm 0.11 & 0.17 \pm 0.05 & 1.8 \pm 0.06 & 1.2 \pm 0.35 & 0.50 \pm 0.08 & 0.39 \pm 0.06\end{array}$

Eyes Closes

$\begin{array}{lccccccc}\text { Pre-M Control } & 1.81 \pm 0.91 & 0.32 \pm 0.07 & 0.20 \pm 0.06 & 2.1 \pm 0.39 & 1.4 \pm 0.51 & 0.68 \pm 0.17 & 0.43 \pm 0.10 \\ \text { Post-M Control } & 1.73 \pm 0.71 & 0.31 \pm 0.07 & 0.19 \pm 0.05 & 2.1 \pm 0.44 & 1.3 \pm 0.36 & 0.65 \pm 0.14 & 0.42 \pm 0.07 \\ \text { Pre-M TMD } & 2.12 \pm 2.04 & 0.31 \pm 0.13 & 0.22 \pm 0.09 & 2.1 \pm 0.82 & 1.6 \pm 0.72 & 0.68 \pm 0.15 & 0.47 \pm 0.11 \\ \text { Post-M TMD } & 1.73 \pm 1.92 * & 0.29 \pm 0.14 & 0.18 \pm 0.06^{*} & 2.0 \pm 0.92 & 1.4 \pm 0.62 * & 0.63 \pm 0.17 * & 0.43 \pm 0.12 *\end{array}$

"Shows significant difference $(\mathrm{p}<0.05)$ between the TMD group pre-mobilization (pre-M) and post-mobilization (post-M) using the Wilcoxon signed-rank test. *Indicates a significant difference $(\mathrm{p}<0.05)$ between TMD Group pre-mobilization $($ Pre $\mathrm{M})$ and post-mobilization $($ Post M) by the Wilcoxon test. 
Thus, the decreased values noted in this study, although non-significant for most $\mathrm{CoP}$ variables, strengthen the evidence regarding the effect of TMJ mobilization because body sway significantly increases in healthy subjects with closed eyes ${ }^{48}$.

Overall, the visual system also integrates the postural system because it contributes to the preventive and compensatory corrections for balance and posture ${ }^{29,30}$. The main function of the visual system is the late stabilization of postural corrections and planning anticipatory reactions $\mathrm{s}^{50}$.

Furthermore, anatomical evidence also indicates that trigeminal nucleus neurons are projected onto the vestibular nuclei controlling the motor function of the eyes and head and receiving information regarding the extra-ocular and neck muscles ${ }^{27}$.

This evidence indicates that sensory information from TMJ proprioceptive receptors and masticatory muscles is processed jointly with the information from the vestibular and oculomotor systems ${ }^{27}$.

Thus, closed eyes should generate a delay in postural corrections and, consequently, an increase in stabilometric parameters, but the afferent stimulus provided by the NMM of TMJ may have contributed to an opposite response to that observed in studies exclusively controlling eyesight $t^{49-51}$.

Therefore, the results of this study may be related to alterations in the trigeminal afferent system, which reflexively has a downward action on the postural muscles and may have caused the decrease in the oscillatory parameters studied.

This action was most evident in the TMD group without visual afference, indicating the possibility that the continuous inhibition of nociceptive impulses arising from TMD-related dysfunction somehow enhances the effect of the central nervous system on postural control.

This idea strengthens the hypothesis that eyesight compensates, at least partially, for the possible deficit in postural control in subjects with DTM, which may indicate that the NMM action only becomes evident in the absence of eyesight.

However, these results still fail to clarify the physiological mechanisms involved in the process, and this caveat is related to the methodology used in this study.

This pitfall might be ameliorated if individuals would have been re-evaluated on consecutive days, which would enable a better understanding of the immediate effectiveness of TMJ mobilization. The lack of re-testing represents a study limitation that should be reassessed in future studies.

The decrease in CoP, especially in subjects with $\mathrm{TMD}$, is an indication that this type of intervention can contribute to an immediate improvement in the postural control of the subjects, although a better understanding of the effect of mobilizing the TMJ on postural control and an improved methodological study design are still required.

Therefore, claiming that this improvement can contribute to the clinical treatment of patients with TMD is not yet possible. The most appropriate way to address this question would be to observe the potential cumulative effect of the intervention technique following several consecutive treatment sessions towards a clinical indication ensuring nonspecific TMJ mobilization. Moreover, it would also be important to assess other variables, including posture, pain relief, and masticatory function in patients with TMD.

\section{Conclusion}

The study results indicate that nonspecific TMJ mobilization contributes to the immediate improvement in the postural control of subjects with TMD. Furthermore, the decrease in CoP variables observed in subjects with and without TMD suggests an afferent action on the trigeminal system, and this should be further investigated in future studies.

\section{Acknowledgments}

The authors acknowledge São Paulo State Research Foundation (Fundação de Amparo à Pesquisa do Estado de São Paulo, Fapesp) for funding (2011/04748-4).

\section{References}

1. Suvinem TI, Reade PC, Hanes KR, Konone M, Kemppainem P. Temporomandibular disorder subtypes according to self-reported physical and psychicalsocial variables in female parients: a reevaluation. J Oral Rehabil. 2005;32:166-73. http://dx.doi. org/10.1111/j.1365-2842.2004.01432.x

2. Biasotto-Gonzalez DA. Abordagem interdisciplinar das disfunções temporomandibulares. Barueri: Ed. Manole; 2005.

3. Perinetti G, Contardo L. Posturography as a diagnostic aid in dentistry: a systematic review. J Oral Rehabil. 2009;36:922936. http://dx.doi.org/10.1111/j.1365-2842.2009.02019.x

4. Martins RJ. Associação entre classe econômica e estresse na ocorrência da disfunção temporomandibular. Rev Bras Epidemiol. 2007;10(2):215-22. http://dx.doi.org/10.1590/ S1415-790X2007000200009

5. Biasotto-Gonzalez DA, Berzin F. Electromyographic study of patients with masticatory muscles disorders, physiotherapeutic treatment (massage). Braz J Sci. 2004;3(10):516-521. 
6. Siqueira JTT, Teixeira MJ. Dor orofacial e disfunção temporomandibular: abordagem clínica atual. JBO. 1998;3(17):36-50.

7. Moreno BRG, Maluf AS, Marques AP, CrivelloJunior O. Avaliação clínica e da qualidade de vida de indivíduos com disfunção temporomandibular. Rev Bras Fisioter. 2009;13(3):210-214. http://dx.doi.org/10.1590/ S1413-35552009005000028

8. Gonçalves MC, Florencio LL, Chaves TC, Speciali JG, Bigal ME, Bevilaqua-Grossi D. Do women with migraine have higher prevalence of emporomandibular disorders?. Rev Bras Fisioter. 2013;17(1):64-8. http:// dx.doi.org/10.1590/S1413-35552012005000054

9. Manfredini D, Piccotti F, Ferronato G, Guarda-Nardini L. Age peaks of different RDC/TMD diagnoses in a patient population. J Dent. 2010;38(5):392-399. http://dx.doi. org/10.1016/j.jdent.2010.01.006

10. Dworkin SF, Leresche L. Research diagnostic criteria for tempormandibular disorders: review, criteria, examinations and specifications, critique. Cranio. 1992;6:301-355.

11. Kosminsky M, Lucena LBS, Siqueira JTT, Pereira Junior F, Góes PSA. Adaptação cultural do questionário Research Diagnostic Criteria for Temporomandibular Disorders: Axis II para o português. JBC J Bras Clin Odontol Integr. 2004;8:51-61.

12. Pereira Junior FJ, Favilla EE, Dworkin SF, Huggins K. Critérios de diagnóstico para pesquisa das disfunções temporomandibulares (RDC/TMD). Tradução oficial para a língua portuguesa. JBC J Bras Clin Odontol Integr. 2004;8(47):384-95.

13. De Lucena LBS, Kosminsky M, Da Costa LJ, Góes PSA. Validation of the Portuguese version of the RDC/TMD Axis II questionnaire. Braz Oral Res. 2006;20:312-317. http://dx.doi.org/10.1590/S1806-83242006000400006

14. Campos JADB, Loffredo LCM, Faria JB. Internal consistency and reproducibility of portuguese version of research diagnostic criteria for temporomandibular disorders (RDC/TMD-Axis II). Rev Bras Fisioter. 2007;11(6):451-459. http://dx.doi.org/10.1590/ S1413-35552007000600006

15. Haythornthwaite JA. IMMPACT recommendations for clinical trials: opportunities for the RDC/TMD. J Oral Rehabil. 2010;37:799-806. http://dx.doi. org/10.1111/j.1365-2842.2010.02152.x

16. Campos JADB, Gonçalves DAG, Camparis CM, Speciali JG. Confiabilidade de um formulário para diagnóstico da severidade da disfunção mporomandibular. Rev Bras Fisioter. 2009;13(1):38-43. http://dx.doi.org/10.1590/ S1413-35552009005000007

17. Bracco P, Deregibus A, Piscetta R. Effects of different jaw relations on postural stability in human subjects. Neurosci Lett. 2004;256:228-230. http://dx.doi.org/10.1016/j. neulet.2003.11.055

18. Gangloff P, Perrin PP. Unilateral trigeminal anaesthesia modifies postural control in human subjects. Neurosci Lett. 2002;330:179-182. http://dx.doi.org/10.1016/ S0304-3940(02)00779-6

19. Michelotti A, Buonocore G, Farella M, Pellegrino G, Piergentili C, Altobelli S, et al. Postural stability and unilateral posterior crossbite: is there a relationship?
Neurosci Lett. 2006;392:140-144. http://dx.doi. org/10.1016/j.neulet.2005.09.008

20. Perinetti G. Dental occlusion and body posture: no detectable correlation. Gait Posture. 2006;24:165-168. http://dx.doi.org/10.1016/j.gaitpost.2005.07.012

21. Tardieu C, Dumitrescu M, Giraudeau A, Blanc J, Cheynet F, Borel L. Dental occlusion and postural control in adults. Neurosci 1Lett. 2009;450:221-224. http://dx.doi. org/10.1016/j.neulet.2008.12.005

22. Okeson JP. Management of Temporomandibular Disorders and Occlusion. 7th ed. Elsevier; 2012.

23. Klineberg I, Murray G. Osseoperception: sensory function and proprioception. Adv. Dent. Res. 1999;13:120-9. http:// dx.doi.org/10.1177/08959374990130010101

24. Lobbezoo F, Trulsson M, Jacobs R, Svensson P, Cadden SW, Van Steenberghe D. Topical review: modulation of trigeminal sensory input in humans: mechanisms and clinical implications. J Orofac Pain. 2002;16:9-21

25. Kido MA, Kiyoshima T, Ibuki T, Shimizu S, Kondo $\mathrm{T}$, Terada Y, et al. A topographical and ultrastructural study of sensory trigeminal nerve endings in the rat temporomandibular joint as demonstrated by anterograde 171 transport of wheat germ agglutinin-horseradish peroxidase (WGA-HRP). J Dent Res. 1995;74:1353-1359. http://dx.doi.org/10.1177/00220345950740070601

26. Shinoda M, Ozaki N, Asai H, Nagamine K, Sugiura $\mathrm{Y}$. Changes in $\mathrm{P} 2 \mathrm{X} 3$ receptor expression in the trigeminal ganglion following monoarthritis of the temporomandibular joint in rats. Pain. 2005;116:42-51. http://dx.doi.org/10.1016/j.pain.2005.03.042

27. Pinganaud G, Bourcier F, Buisseret-Delmas C, Buis-Seret P. Primary trigeminal afferents to the vestibular nuclei in the rat: existence of a collateral projection to the vestibulocerebellum. Neurosci Lett. 1999;264:133-136. http:// dx.doi.org/10.1016/S0304-3940(99)00179-2

28. Monzani D, Guidetti G, Chiarini L, Setti G. Combined effect of vestibular and craniomandibular disorders on postural behavior. Acta Otorhinolaryngol Ital. 2003;23:4-9.

29. Schmid M, Casablanca L, Bottaro A, Schieppati M. Graded changes in balancing behavior as a functional of visual acuity. Neuroscience 2008;153:1079-91. http:// dx.doi.org/10.1016/j.neuroscience.2008.03.024

30. Mohapatra S, Krishnan V, Aruin AS. The effect of decreased visual acuity on control of posture. Clin Neurophysiol. 2012;123(1):173-82. http://dx.doi. org/10.1016/j.clinph.2011.06.008

31. Reis LGK, Bérzin F. Analysis of the postural stability in individuals with or without signs and symptoms of temporomandular disorder. Braz Oral Res. 2008;22:378-383.

32. Townsen D, Nicholson RA, Buenaver L, Bush F, Gramling S. Use of a habit reversal treatment for temporomandibular pain in a minimal therapist contact format. J Behav Ther Exp Psychiatry. 2001;32:221-39. http://dx.doi. org/10.1016/S0005-7916(02)00004-6

33. Michelotti A, Steenks MH, Farella M, Parsini F, Cimino $\mathrm{R}$, Martina $\mathrm{R}$. The additional value of a home physical therapy regimen versus patient education only for the treatment of myofascial pain of the jaw muscles: short 
term results of a randomized clinical trial. J Orofac Pain. 2004;18:114-25.

34. Mcneely ML, Armijo OS, Magee DJ. A systematic review of the effectiveness of physical therapy for temporomandibular disorders. Phys Ther. 2006;86:710-25.

35. Cuccia AM, Caradonna C, Annunziata V, Caradonna D. Osteopathic manual therapy versus conventional conservative therapy in the treatment of temporomandibular disorders: A randomized controlled trial. J Mov Bodyw. 2010;14(2):179-84. http://dx.doi.org/10.1016/j. jbmt.2009.08.002

36. Polso H, Napankangas R, Raustia AM. Treatment Outcome in patients with TMD - A survey of 123 patients Referred to specialist care. Cranio. 2010;28(3):156-65.

37. Oliveira LF, Simpson DM, Nadal J. Calculation of area of stabilometric signals using principal component analysis. Physiol Meas. 1996;17:305-312. http://dx.doi. org/10.1088/0967-3334/17/4/008

38. Kantner RM, Rubin AM, Armstrong CW, Cummings V. Stabilometry in balance assessment of dizzy and normal subjects. Am J Otolaryngol. 1991;12(4):196-204. http:// dx.doi.org/10.1016/0196-0709(91)90120-5

39. Riach CL, Starkes JL. Velocity of centre of pressure excursions as an indicator of postural control systems in children. Gait \& Posture. 1994;2:167-172. http://dx.doi. org/10.1016/0966-6362(94)90004-3

40. Gravelle DC, Laughton CA, Dhruv NT, Katdare KD, Niemi JB, Lipsitz LA, et al. Noise-enhanced balance control in older adults. Neuro Report. 2002;13(15):1853-1956. http:// dx.doi.org/10.1097/00001756-200210280-00004

41. Kritsineli M, Shim YS. Malocclusion, body posture, and temporomandibular disorder in children with primary and mixed dentition. J Clin Pediatr Dent. 1992;16:86-93.

42. Gangloff P, Louis JP, Perrin P. Dental occlusion modifies gaze and pos- ture stabilization in human subjects. Neurosci Lett. 2000;293:203-6. http://dx.doi.org/10.1016/ S0304-3940(00)01528-7

43. Milani RS, De Periere DD, Lapeyre L, Pourreyron L. Relationship between dental occlusion and posture. Cranio 2000;18:127-34.
44. Dessem D, Taylor A. Morphology of jaw-muscle spindle afferents in the rat. J Comp Neurol. 1989;282:389-403. http://dx.doi.org/10.1002/cne.902820306

45. Lee WY, Okeson JP, Lindroth J. The relationship between forward head posture and temporomandibular disorders. J Orofac Pain. 1995;9:161-7.

46. Fernández-de-las-Peñas C, Cuadrado ML, Pareja JA. Myofascial trigger points, neck mobility and forward head posture in unilateral migraine. Cephalalgia. 2006;26:106170. http://dx.doi.org/10.1111/j.1468-2982.2006.01162.x

47. Ishii H. A study on the relationships between imbalance of stomatognathic function and asymmetry of craniofacial morphology, and the center of gravity of the upright posture. Osaka Daigaku Shigaku Zasshi. 1990;35:517-56.

48. Duarte M, Zatsiorsky VM. Effects of body lean and visual information on the equilibrium main- tenance during stance. Exp Brain Res. 2002;146:60-69. http://dx.doi. org/10.1007/s00221-002-1154-1

49. Vallis LA, Patla AE, Adkin AL. Control of steering in the presence of unexpected head yaw movements. Exp Brain Res. 2001;138:128-34. http://dx.doi.org/10.1007/ s002210100680

50. Elliott JE, Fitz G, Murray A. Postural stability of normal subjects measured by sway magnetometry: pathlength and area for the age range 15 to 64 years. Physiol Meas. 1988;19:103-109. http://dx.doi. org/10.1088/0967-3334/19/1/009

51. Vuillerme N, Nougier V, Prieur JM. Can vision compensate for a lower limbs muscular fatigue for controlling posture in humans? Neurosc Lett. 2001;308:103-106. http://dx.doi. org/10.1016/S0304-3940(01)01987-5

\section{Correspondence}

\section{Ana Paula Amaral}

Av. Raimundo Pereira de Magalhães, 1720

Apto 62, bloco 25, Jardim Íris

CEP 05145-000, São Paulo, SP, Brazil

e-mail: ap.fisioterapeuta@gmail.com 